\title{
Spontaneous perforation of the subvesical bile duct
}

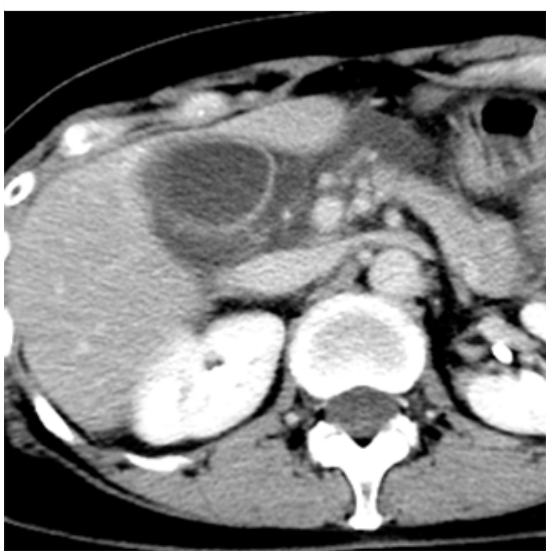

- Fig. 1 Abdominal computed tomography scan showing a localized fluid collection at the hepatic hilum in a 57-yearold woman who presented with acute upper abdominal pain.

Subvesical bile ducts, which are frequently incorrectly termed "ducts of Luschka," traverse within, or in close contact with, the gallbladder fossa [1]. They are one of the most common etiologies of bile leak in cholecystectomy and have gained increased clinical attention in the present laparoscopic era. Subvesical bile ducts are hardly ever detected preoperatively because their mean diameter is $2 \mathrm{~mm}$ [1]. Indeed, in most patients, subvesical bile duct leaks are detected postoperatively, generally during the first postoperative week [2]. This report describes a case of spontaneous perforation of the subvesical bile duct.

A 57-year-old woman was admitted to our department with acute upper abdominal pain. She described the pain as having worsened over the previous 24 hours, followed by a sudden, sharp pain in her right upper quadrant. Computed tomography (CT) scanning revealed a localized fluid collection at the hepatic hilum ( $>$ Fig.1). Given the location of this collection, perforation of the gallbladder or bile ducts was suspected. An urgent endoscopic retrograde cholangiography (ERC) was performed, during which extravasation of contrast out of a

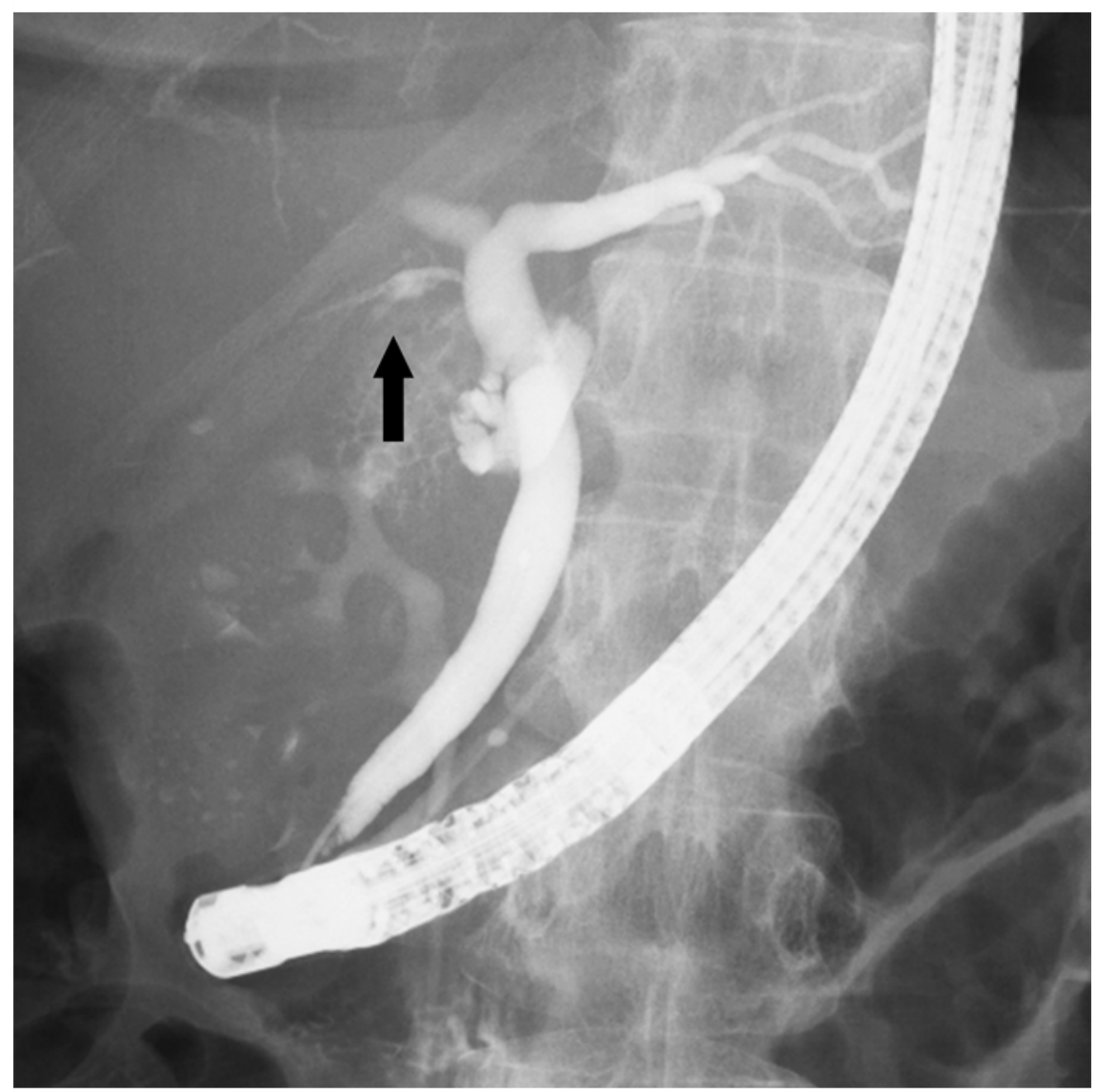

- Fig. 2 Cholangiographic image showing extravasation of contrast out of the subvesical bile duct (arrow).
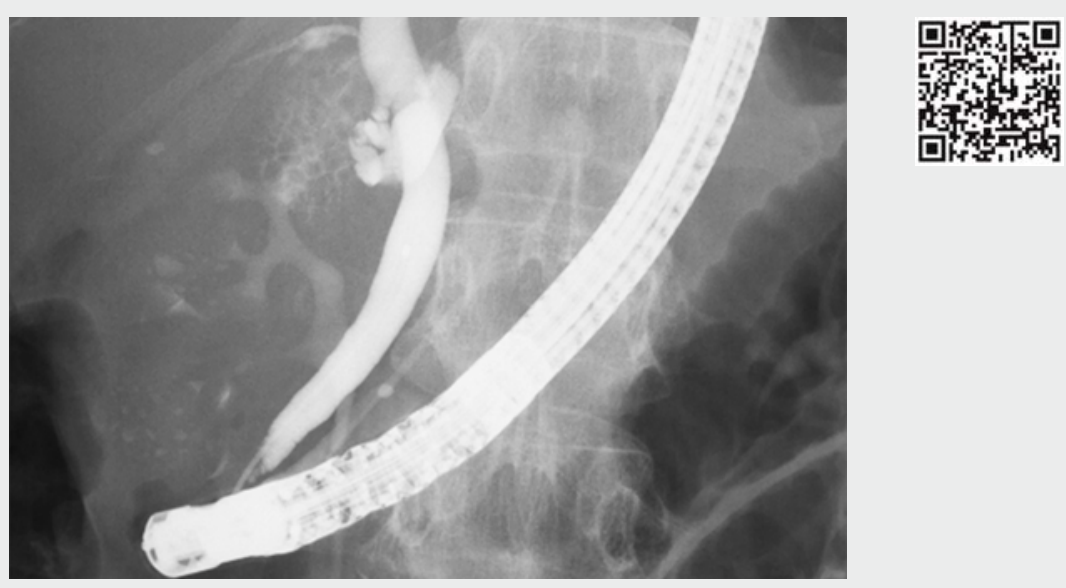

$\checkmark$ Video 1 An urgent endoscopic retrograde cholangiography revealed extravasation of contrast out of the subvesical bile duct on fluoroscopy. 
subvesical bile duct was identified on fluoroscopy ( $>$ Fig. 2; $>$ Video 1). A diagnosis of biliary peritonitis due to spontaneous perforation of the subvesical bile duct was confirmed, and endoscopic nasobiliary drainage was performed.

Cholangiography through the nasobiliary drainage tube 9 days later confirmed healing of the bile leak. The patient was discharged without complications following removal of the drainage tube. The subvesical bile duct with traces of the bile leak was subsequently found and ligated during an elective open cholecystectomy.

Spontaneous perforation of bile duct in adults is extremely rare and the most common perforation site is the common bile duct. To our knowledge, this is the first case of spontaneous perforation of a subvesical bile duct.

Endoscopy_UCTN_Code_TTT_1AO_2AM

Competing interests
The authors

Sho Kitagawa, Kana Hatayama, Keiya

Okamura

Department of Gastroenterology, Sapporo Kosei

General Hospital, Sapporo, Japan

\section{Corresponding author}

\section{Sho Kitagawa, MD}

Department of Gastroenterology, Sapporo Kosei General Hospital, Kita 3 Higashi 8, Chuo-ku, Sapporo 060-0033, Japan

Fax: +81-11-2715320

bossa0405@yahoo.co.jp

\section{References}

[1] Schnelldorfer T, Sarr MG, Adams DB. What is the duct of Luschka? - A systematic review. J Gastrointest Surg 2012; 16: 656-662

[2] Spanos CP, Syrakos T. Bile leaks from the duct of Luschka (subvesical duct): a review. Langenbecks Arch Surg 2006; 391: 441 447

\section{Bibliography}

DOI https://doi.org/10.1055/a-0573-0685

Published online: 8.3.2018

Endoscopy 2018; 50: E140-E141

(c) Georg Thieme Verlag KG

Stuttgart · New York

ISSN 0013-726X

\section{ENDOSCOPY E-VIDEOS}

https://eref.thieme.de/e-videos

回局 Endoscopy E-Videos is a free access online section, reporting 靣艘: on interesting cases and new techniques in gastroenterological endoscopy. All papers include a high quality video and all contributions are freely accessible online.

This section has its own submission website at https://mc.manuscriptcentral.com/e-videos

None 